\title{
Contribution of the Newborn Behavioral Observations (NBO) for the maternal care of preterm neonates
}<smiles>[GeH3]</smiles>

${ }^{1}$ Hospital Sofia Feldman

${ }^{2}$ Departamento de Pediatria da Faculdade de Medicina da Universidade Federal de Minas Gerais

${ }^{3}$ Departamento de Enfermagem Materno-Infantil e Saúde Pública da Escola de Enfermagem da Universidade Federal de Minas Gerais

${ }^{4}$ Departamento de Terapia Ocupacional da Universidade Federal de Minas Gerais

\section{Corresponding author:} erikadittz@gmail.com

Manuscript received: September 2017 Manuscript accepted: November 2017 Version of record online: December 2017

\author{
Erika da Silva Dittz¹, Claudia Regina L. Alves², Elysângela \\ Dittz Duarte ${ }^{3}$, Lívia de Castro Magalhães ${ }^{4}$
}

\begin{abstract}
Introduction: In the care of preterm newborn, practices that favor the participation of mothers in care are recommended. The use of appropriate instruments by professionals can contribute to strengthen maternal participation.
\end{abstract}

Objective: To analyse the contributions of the use of the Newborn Behavioral Observations (NBO) for the maternal care of preterm neonates

Methods: Descriptive qualitative study, using participant observation and semi-structured interviews with 14 mothers of preterm newborns who underwent NBO. Data was submitted to content analysis, assinted by the software MAXQda 12 .

Results: It was found that the mothers' prior perceptions of the newborn's capacities or how they react to environmental stimuli do not differ from what was observed and reported by them after NBO. However, it was verified that NBO confirms this perception and broadens the mothers' understanding of the meaning of the newborn's behavior. Participating in the NBO helped the mothers to identify strategies to find the needs of the newborn, qualifying the care already performed by them and opening new possibilities for maternal care.

Conclusion: The NBO is an instrument that favors the mother's learning about the behavior of the newborn and contributes to the construction of practices with potential to be used by them within daily care. This allows us to consider it as a tool that favors the mother-baby relationship, contributes to the mother's participation in the care, and supports the mother in the construction of her autonomy for the continuity of the newborn's care after hospital discharge.

Keywords: preterm, mother-child interaction, mothers, maternal behavior, baby care 


\section{INTRODUCTION}

Preterm birth can be a source of suffering and stress for mothers and families ${ }^{1}$. The severity of the clinical condition of the neonates hospitalized in the Neonatal Intensive Care Unit (NICU) can cause apprehension in the parents and impair the establishment of the bond. Parents may find it difficult to interact with the preterm newborn since children with physiological, motor, or sensory instability may respond to stimuli with unpredictable behaviors that are hard to recognize and interpret ${ }^{2}$.

In addition, the inability to perform the typical tasks of parental care are potential stressors for mothers, and may negatively influence their ability to learn about the care required by the newborn and prepare to take care after hospital discharge ${ }^{3}$.

The stress experienced by the parents of hospitalized newborns is more intense in the period immediately after the admission of the newborn in the NICU and in the period of transition from the hospital to the home ${ }^{3}$. Part of the stress experienced in the prior period to hospital discharge is related to insecurity to assume the role of parents, reintroducing the need to consider the implementation of strategies to support families ${ }^{3}$.

Engaging parents in care and counseling them about the behavior of their preterm infants can enhance the bond between them ${ }^{4}$. Interventions have been investigated in order to foster interaction between parents and their children, based on the premise that it is established and strengthened as parents know and understand the behavioral signs of the newborn ${ }^{5-8}$.

An instrument that has favored the engagement of women in the maternal role is the Newborn Behavioral Observations (NBO). It is a protocol for observing newborn behavior in partnership with parents, which, when used in the Joint Housing by primiparous women in the postpartum period, favored the bond between mother and newborn, contributed to the mothers to increase their knowledge of newborn children and what to do to meet

\section{METHODS}

This is a qualitative study of the descriptive type, which is part of the research entitled "Evaluation of child development and early intervention in high-risk children and their families in Brazil’.

The data were collected at Casa do Bebê, an extra-hospital unit belonging to the reference hospital for maternal and child care in Belo Horizonte, Minas Gerais. The house is located in the vicinity of this institution and is intended for non-hospital follow-up of clinically stable newborns, gaining weight that are $1500 \mathrm{~g}$ or greater and corrected for gestational age $>34$ weeks, without enteral feeding, in phototherapy without early jaundice and no risk for exchange transfusion, newborns without evident neurosensory deficits, syndromic, without gastrostomy and/or tracheostomy.

The Data collection at Casa do Bebê was performed from September 1 to October 10, 2015. We included 14 their needs ${ }^{9,10}$. In addition, NBO has been shown to be an instrument that encourages mothers to actively participate in care $^{10}$.

Developed from the Neonatal Behavioral Assessment Scale (NBAS) ${ }^{11}$, NBO is an individualized, family-centered, child-focused observation that can be used with children from zero to three months of age. The NBO consists of 18 items that enable the identification of the behavioral signs of the child, that is, their ability to become accustomed to repeated stimuli; regulate motor activity and behavioral state changes; responding to stress during handling; to orient themselves in relation to the visual and auditory stimuli and to establish social interaction. The goal of the NBO is to strengthen the relationship between parents and children and promote a supportive relationship between health professionals and their families ${ }^{12}$. Because it is a flexible instrument with few items, it can be easily incorporated into the newborn care routine ${ }^{13}$

Considering the context of the care offered to preterm infants in Brazil, there are health policies and a legal apparatus that create conditions for the insertion of the family in the care of the newborn throughout the hospitalization period ${ }^{14}$. However, even if there are strategies that favor mothers 'participation in care, it is not explored in their potential, indicating the need to broaden the studies, solidify existing practices and move forward in the construction of new alternatives for mothers' participation in care ${ }^{15}$.

Therefore, it is assumed that maternal participation in the care of the preterm newborn can be enhanced when health professionals use instruments that reaffirm and expand the parents' knowledge about the behavioral signs of the newborn, increased confidence in post-discharge care. Considering the stress associated with prematurity, this study aimed to analyze the contributions of the use of $\mathrm{NBO}$ to the maternal care of preterm infants.

mothers of newborns with gestational age $<37$ weeks, who remained for at least three days at Casa do Bebê. Participating mothers were identified in the recruitment registry of the original research sample and all eligible mothers were included.

Participant observation and semi-structured interviews were performed to collect data. Participant observation occurred during the $\mathrm{NBO}$ and sought to describe aspects related to the location, dynamics of NBO and the interactions established between mother, newborn and health professionals during their accomplishment. The duration of the observation was determined by the beginning and end of the NBO, with an average duration of 33 minutes, and records were made in the field diary by the researcher. All observations were made in the child's bed, in the presence of the mother, the professional who performed the NBO and the researcher. 
It is worth noting that a NBO version was used transculturally adapted to Brazilian Portuguese ${ }^{16}$, and the NBO was performed by professionals trained and certified by The Brazelton Institute.

The semi-structured interview sought to explore the mothers' learning about the newborn's behavior and ways to help him when he is uncomfortable or crying. The guiding questions of the interview were elaborated from aspects contemplated in the Parent Questionnaire, which is part of the NBO (Table 1). The interviews

Table 1:Guiding questions of semi-structured interview with mothers

\section{GUIDING QUESTIONS}

1. During this observation, did you learn something new about your baby? What?

2. Do you think this observation allowed you to find ways to help your baby when he is uncomfortable or crying? Which are they?

3. After you participate in this observation, would you change anything in the way you do your day-to-day care of your baby? What?

were performed immediately after NBO, had an average duration of four minutes and were recorded, transcribed by the researcher and reviewed for accuracy. The data collection protocol was tested with a mother who did not participate in the study, in order to verify the adequacy of the aspects to be observed and the interview script, and no need for modifications was identified.

The data were transcribed and organized, as they were collected, allowing the researchers to perform preliminary analysis. Data collection was interrupted when the data was saturated ${ }^{17}$, so that they already provided enough elements to respond to the objectives of the study and to contribute to the production of knowledge about the subject.

The data were submitted to conventional content analysis, as described by Hsieh and Shannon ${ }^{18}$, using
MaxQ software version ${ }^{12}$. Two independent researchers, who read the transcription of the interviews and the reports of the observations, highlighting the themes the NBO contributions to the maternal care of the newborn, analyzed the data.

From the identified themes, the researchers defined preliminary categories, subcategories and continued the exploration of the material identifying the themes and allocating them in the corresponding categories. The two researchers then met to review the material and discuss questions regarding the categorization of the data. After this stage the concordance agreement was verified (Kappa $0,75)$. The groupings of data into empirical categories and subcategories were validated by a third researcher, and are presented in Table 2.

Table 2: Empirical Categories and Subcategories identified in mothers' reports. Belo Horizonte, Minas Gerais, Brazil, 2016.

\begin{tabular}{ll}
\hline Categorie & Subcategorie \\
\hline - The knowledge about the preterm newborn and the & - Knowledge of the mother about the preterm \\
care practices performed by the mothers in the care of & newborn and her abilities before the NBO \\
the newborn before the NBO. & - Care practices performed by mothers before the \\
& NBO \\
- The use of NBO as a possibility for the learning and & - Learning about the preterm newborn and her \\
qualification of the care performed by the mother. & $\begin{array}{l}\text { capabilities made possible by the NBO } \\
\text { - Care practices with potential to be adopted by } \\
\end{array}$ \\
\hline
\end{tabular}

In the description of the data, matrices with the themes that composed each subcategory were constructed, which allowed to identify discrepancies and similarities in the reports of the participants.

In the development of this study, it was tried to meet the criteria of credibility, reliability and confirmability ${ }^{19}$. Credibility was established through peerto-peer discussion and triangulation of data generated from participant observation, interview, and survey in the medical record. For the discussion between pairs, the two researchers shared their impressions about interview data and participant observation, broadening the understanding about the phenomenon studied and contributing to the process of data analysis and interpretation. The reliability criterion was met through the codification of the data by two independent researchers, being this process, as well as the preliminary results of the research, examined by an external researcher. For confirmability a detailed description of the entire research process was carried out, including the definition of the participants, the instruments of data collection and the process of data analysis, seeking a certain degree of neutrality and reducing the researcher's bias. Also with regard to confirmability, the analysis process was permeated by discussions among the researchers, seeking to identify divergent or complementary perceptions, which contributed to explore the data in depth.

The project was approved by the Ethics and 
Research Committee of the Federal University of Minas Gerais (COEP / UFMG) and by the Research Ethics Committee of the Hospital Sofia Feldman (CEP / HSF) (CAAE 29437514.1.0000.5149). All the participants of the research were clarified on the procedures and objectives of the study and signed a Term of Free and Informed Consent (TCLE). In addition, for the present study, each participant was approached by the researcher

\section{RESULTS}

The Newborn Behavioral Observations (NBO) was performed with 14 mothers aged between 19 and 42 years and mean of $32 \pm 6.97$ years; $9(64.3 \%)$ were primiparous and $11(78.6 \%)$ attended the school for 8 years or more. Among preterm infants, $11(78.6 \%)$ had GI less than 33 weeks, 5 (35.7\%) were born with a weight before performing the NBO, requesting authorization to observe and do the interview. All the mothers agreed to participate. In order to preserve anonymity, participants were identified with the letter " $\mathrm{M}$ " followed by the numerical code referring to the order of interview (E) and participant observation (OP).

Table 3: Characterization of mothers and newborns participating in the study. Belo Horizonte, Minas Gerais, Brazil 2016.

\begin{tabular}{ccccccc}
\hline Mom & $\begin{array}{l}\text { Maternal } \\
\text { age }\end{array}$ & $\begin{array}{l}\text { Maternal education } \\
\text { (in years) }\end{array}$ & Parity & $\begin{array}{l}\text { Gestational Age } \\
\text { (in weeks) }\end{array}$ & $\begin{array}{l}\text { Weight NB } \\
\text { at Birth (in } \\
\text { grams) }\end{array}$ & $\begin{array}{l}\text { NB feeding } \\
\text { type }\end{array}$ \\
\hline M1 & 23 & 4 & 1 & 33 & 1.225 & EBF \\
M2 & 27 & 11 & 1 & 34 & 1.180 & EBF \\
M3 & 22 & 9 & 2 & 29 & 910 & EBF \\
M4 & 19 & 11 & 1 & 33 & 2.110 & EBF \\
M5 & 40 & 4 & 8 & 31 & 1.665 & EBF \\
M6 & 20 & 11 & 1 & 35 & 2.380 & EBF \\
M7 & 34 & 5 & 1 & 30 & 1.700 & EBF \\
M8 & 35 & 11 & 2 & 30 & 845 & ML \\
M9 & 36 & 16 & 1 & 32 & 2.165 & ML \\
M10 & 28 & 8 & 2 & 30 & 1.665 & EBF \\
M11 & 34 & 11 & 1 & 32 & 1.350 & EBF \\
M12 & 38 & 11 & 3 & 34 & 1.800 & ML \\
M13 & 24 & 11 & 1 & 32 & 1.545 & ML \\
M14 & 30 & 8 & 1 & 33 & 1.705 & EBF \\
\hline
\end{tabular}

Note: $\mathrm{EBF}=$ Exclusive breastfeeding, $\mathrm{ML}=$ Mixed Lactation

The knowledge about the newborn and the care practices performed by the mother in the care of the newborn before the NBO.

This category evidenced the mothers' knowledge of the newborn as well as what they did to find their needs. The process of data organization and analysis allowed us to identify two subcategories described below.

\section{Knowledge of the mother about the newborn and its abilities before the NBO}

Mothers revealed to have knowledge about the newborn, whether related to their abilities or how they responded to the stimuli of the environment. 10 mothers, especially from the participant observations, evidenced these aspects.

Seven mothers expressed knowledge about signs of discomfort and stress. For them, aspects related to the less than 1500 grams. None of the children studied had any signs of neurological changes. Regarding the feeding of the newborns, $10(71.4 \%)$ were exclusively breastfed (SMA) and the others receiving breast milk and formula. In Table 3 we present a more detailed characterization of each participant. 
following with their eyes. The ability of the newborn to perceive the mother's voice is expressed by mothers as something they had already realized, which was reinforced during the NBO.

The researcher asks the mother if she usually talks to the newborn. She says yes and when she talks to him, he keeps paying attention. (M5, OP).

The mother was invited to talk with her son. At that moment, the child searches for his mother until he finds her. The mother shows pride in her son, and reinforces that she always talks to him and he responds. (M10, OP).

The ability of the newborn to become accustomed to the auditory stimulus is perceived by one of the mothers, who considered that this was due to the fact that the newborn had been exposed for some time to the noise of the hospital environment.

When the auditory stimulus is offered, the mother observes, laughs and comments that in the Intermediate Care Unit (ICU) there was a lot of noise and then she [daughter] can not be bothered (M2, OP).

Aspects related to the growth and development of the newborn were perceived by the mothers, who mentioned the weight gain and the motor acquisitions.

The researcher asks the mother what she can tell about her newborn since birth. The mother says that he became fat and grew. (M5, OP).

The mother reports that she has observed evolution in the child since birth as the control of head and neck. He is now able to tighten his neck when he has something that interests him. (M10, OP).

Mothers have demonstrated knowledge about the newborn's behavior when he or she wants to breastfeed, either through crying or through suctioning. Suction was also expressed by mothers as a strategy used by the newborn to calm down.

During the sucking stimulus, the child resists and does not suck. The mother says it's because she is not hungry, because when she is, she always sucks. (M2, OP).

When the stimulus for sucking (NBO) is observed the mother says that everything for her is chest and says that the daughter has the habit of bringing the hand to the mouth to suck. (M3, OP).

The researcher asks the mother about the behavior of the newborn. The mother says that he is very quiet, rarely cries, and cries more when he wants to suck. (M5, $O P)$.

\section{Care practices performed by mothers before the NBO}

It was observed that, before the NBO, eight mothers adopted care practices aimed at offering comfort to the newborns from the tacit knowledge they had about the behavior of the newborn. This information was obtained especially through participant observation, which allowed to know what the mothers did to meet the needs of newborns.

Mothers sought to calm their newborns when they were uncomfortable or crying and for that they used, as their main resource, the conversation that seems to produce effects that contribute to the organization of the newborn. The data also showed that the newborn responds to the mother's voice using non-verbal language:

During several moments of observation, the newborn whimpers and when the mother talks, he calms down. (M13, OP).

The researcher asks the mother if she usually talks to the newborn. She says yes and when she talks to him, he keeps paying attention. (M5, OP).

The mother says that she is talking and that in these moments the daughter is following with the eye. He smiles when he sees his daughter do the same with the researcher (follow with the eye). (M2, OP).

Touching the newborn or holding him on his lap is also the way that mothers have found to offer safety and reassure the newborn.

So, I think he feels more secure when I touch him... when I stimulate him in some other way. (M10, E).

The mother gets up from the bed and, as she prepares the materials for the diaper change, looks at her daughter and calls her by name. During the change of diaper, when realizing that the daughter moves in a disorganized way, promptly tries to assist her, calling her by the name and holding her in the lap. The child calms down on his mother's lap. (M1, OP).

One of the mothers expressed that it offered visual stimulation during the interaction with the newborn.

She says she likes to show objects to her son and asks if she can keep doing it. (M10,OP)

In situations where it is necessary to help the newborn in the behavioral state transition, the mothers talked and moved the arms and legs of the newborns, indicating that they adopted these practices in the daily routine when they needed the newborn to be alert to engage in activities such as food.

The researcher who performs the NBO asks her mother what she does to wake up John when she needs to breastfeed him and she tells him to talk to him. (M9, OP).

The researcher attempts to make the transition from behavioral status of the newborn to alertness and the child continues to sleep. The mother tells the researcher to move her daughter's arms and legs as she had been guided by the team during the newborn's hospitalization at the NICU. As the researcher can not wake up the newborn the mother does, calling him by name and moving his arms and legs. (M1, OP).

This last report allows us to consider that the use of these strategies by the mothers may be related to the learning acquired during the period of hospitalization of the newborn in the hospital environment.

\section{The use of NBO as a possibility for the learning and qualification of the care performed by the mother}

This category was divided into two subcategories that, although well delineated, are intimately related and complementary, since what mothers know about the newborn is what seems to direct what they do to meet their needs.

\section{Learning about the newborn and its capabilities made possible by the NBO}

All mothers who participated in the observation 
considered that it enabled them to gain some knowledge about the newborn. The reports show that the knowledge acquired after NBO is related to the newborn's abilities as well as aspects of the environment and the interaction with the newborn.

Participating in the NBO was perceived by mothers as an opportunity to learn about the newborn with the newborn itself. To experience motherhood for the first time, plus the fact that the newborn was preterm, seemed to contribute to the mothers' appreciation of each discovery about the newborn. Maternal availability for discovery and learning with the newborn from birth was evident.

I learned a lot of things with her... It's good to always learn things with the baby... they teach us and we teach them... (M1, E)

I learned... I learned so... every little thing that... for me it's all news because it's my first [daughter] and I did not know anything... I had never seen a premature baby, so for me it's... I'm learning a lot. (M7, E)

The importance of observing the newborn and what he has to say through his behavior was an expressed learning by the mothers. By observing the children the mothers learned about them and their preferences. The mothers' report revealed that there seems to be understanding that the newborn has an individuality. Thus, making use of NBO as an instrument to understand the newborn can be a way to support them to know it in their uniqueness.

I think it helped to think more when he's crying... to see that it's something... to see if it's because he's got the dirty diaper... the will to suck... $(M 4, E)$

Watch him... to see what he wants. (M6, E)

Learning from her too... her little things, what time she wants to suckle, what time she gets nervous... the way she sleeps. I'll get her way by now. $(M 7, E)$

$(M 9, E)$

I've learned the signs he can give... that he's wet

This is evident in the reports of mothers describing the behavior of the newborn in relation to the sonorous and luminous stimuli, showing surprise about their ability to react to the stimuli and to follow what happens in the world around them.

That she can observe us I did not know. I knew she could see, but I did not know it was that way... that she could pay attention to sounds, to light, and to the movements she made. (M3, E)

By the time she passed the little light she [daughter] did so [M12 moves her head from side to side] back and forth with her head.

Researcher: And what does this mean for you?

M12: that it is lit, right... lit for the things that are happening around it. (M12, E)

Observing the newborn being exposed to stimuli and how he reacts also helped the mothers to identify some care to be taken to avoid excessive stimulation.

$\mathrm{A} h . .$. I was noticing that he does not like the same mess. He likes to be more quiet, in his own... (M5, E)

I think the issue of the environment, of the noise ... that it is necessary a more cozy environment. $(M 9, E)$
The mothers realized that the newborns recognize and have a preference for the mother's voice. Even for mothers who reported having observed this ability of the newborn, participating in NBO seems to have made it possible to reinforce this knowledge, especially regarding the newborn's preference for the mother's voice.

I learned that she listens to my voice more... she listens very well... she understands me .. she listens to my voice... $(M 1, E)$

Ah... to stimulate him a little more... to observe also that with me he has more reaction than with others... (M10, E)

The moment he hears my voice he becomes more alert, he is calm. I had already noticed but not so much as at the time she [the researcher] was talking to him and he paid no attention... Now... it was clear to me [referring to the preference for the mother's voice]. (M13, E)

I've learned that he is very fond of talking to him. But I had already realized, but now I realize more... that he stares... $(M 14, E)$

The data show that mothers learn to identify newborn signs that may indicate stress. In addition, the interaction between the professional, the mother and the newborn during the NBO seems to create a favorable environment for the exchange of information, opening the possibility to introduce other knowledge that helps the mother to decipher the meaning of the behavior of the newborn and to serve it more assertively in their needs.

When she's nervous she raises her hand... when someone tries to fiddle with her she cries... $(M 1, E)$

During the NBO the child shows signs of stress with a change in the color of the skin and a sob when pulled to rest. The mother reports that the sob is frequent and does not seem to bother. The researcher, after curling the child and placing it on her lap, suggests that the mother place in the breast to help stop the sobbing. It also explains the causes of the hiccup. The mother is surprised because she did not know that it could be a sign of stress (M11, OP)

\section{Care practices with potential to be adopted by mothers after NBO}

The reports show that, even if immediate repercussions of the NBO are not expected for maternal care, participating in the observation of the newborn allowed mothers to identify ways to favor their development and to help them when they are uncomfortable or crying. Of the 14 mothers, 11 indicated possible practices to be incorporated in the daily care of the preterm newborn.

The positioning was reported by six of them as a strategy to favor the development of the newborn to make it easier to get their hands to their mouth or try new positions.

In case, lay him aside... leave him a little more... for him to reach his mouth with his hand... (M14, E)

Just like she [researcher] put her on her belly down and I had never placed. Just the belly up and the side. So now I'm going to put it more often to stimulate her growth. $(M 3, E)$ 
Observing the newborn has been expressed by mothers as a way of identifying what may be causing them discomfort, especially when they are crying. It also enables mothers to discover newborn preferences and the strategies they use to communicate their needs.

Look if he has a stomach ache... these things... if he's in some pain... if he's feeling bad about anything. What it is... because sometimes it's not just to suck, right... (M4, E)

Watching him more to see what he's wanting. (M6, E)

That part of looking more at what he has, when he has... because his wa ... [...] When he's crying look what it is, to understand him more. (M4, E)

I'm going to play more with her .. pay more attention to her... in the way... in the little things she likes to do... pay more attention to her cry... that's good... (M1, E)

Data collected through participant observation signaled that mothers talked to their children. The achievement of NBO contributed to reinforce this practice as a strategy to be used by mothers to interact or reassure the newborn.

Talk... Talk to her, right... she goes on and on and on... she does not cry... (M2, E)

Just like she started to cry, right? She started to cry and I started talking to her so I could calm her down. Because sometimes she cries and we're in despair, shaking, right... Thinking it's something... and I started to

\section{DISCUSSION}

Data analysis reveals the mothers' knowledge of the newborn and learning about the newborn and its abilities after the Newborn Behavioral Observations (NBO). Practices with potential to be incorporated by mothers in the care of the newborn are identified, expanding and / or qualifying their repertoire of care practices.

Regarding the knowledge that mothers have about the newborn, it is evident that it was acquired through the guidance they receive from the professionals during the hospitalization period and the interaction they establish with the newborns from birth. A systematic review aimed at verifying the effectiveness of interventions performed with parents in improving the relationship between mothers and preterm infants, identified a variety of interventions during the hospitalization period and in the transition to the home. Interventions had mixed results in improving the relationship between mother and child; however, a common aspect was the promotion of maternal care guided by newborn signals ${ }^{20}$, as emphasized in the NBO.

Favoring the parents' learning about the newborn during the hospitalization period is supported by recommendations elaborated for the clinical practice of the health professional assisting this group ${ }^{21}$. These recommendations are based on the understanding that preterm newborns and their families have specific care needs during their hospitalization, so actions are necessary to promote learning about newborn behavior, parental empowerment, and meeting the needs of the newborn. As a result of these actions, there is the reduction of stress and promotion of the mental health of parents as well as the strengthening of the relationship between parents and preterm infants ${ }^{21}$. talk and she stopped crying. (M11, E)

Another practice expressed in the mothers' report was to move or massage the arms and legs of the newborn to stimulate their development. The movement of arms and legs, as well as assisting the newborn to bring the hand to the mouth, was also a way to offer comfort and calm the newborn.

The leg exercise she [researcher] talked about... doing exercise with her leg... (M5, E)

And also massage the little arms and legs that I did not know... so that I could stimulate his little arms and legs so that they would be strong, right? (M10, E)

I watched her cry when she can put her finger in her mouth so she can calm down. (M3, E)

One of the mothers pondered the need to review how the newborn holds, because he noticed that in some situations he reacts with signs of stress. He found that the fact that the baby is preterm and underweight requires that he be more careful.

Sometimes I think I'm too gross to pick up, you know... the attitude of picking him up... to think he's a normal newborn and all, right... I know he's normal, but so... catch him, sometimes he shakes... because of his low weight right... we think he's dealing with a normal weight child and everything. $(M 8, E)$

The interaction between mothers and their newborns is described by the mothers who participated in the present study as a source of learning, as expressed by M1 in stating that "they [children] teach us and we teach them." This fact is reinforced by the assertion that synchrony between mother and child, necessary for the establishment of attachment, develops as mother and child learn from each other, providing feelings of satisfaction and maternal competence ${ }^{22}$.

The NBO is an observation system that aims to help direct the attention of the parents to the communication strategies of the newborn in order to strengthen the relationship between both ${ }^{11}$. The possibility offered by the NBO to integrate parental perceptions about the newborn and to jointly develop a care plan may be a resource to be used by health professionals assisting this group to strengthen maternal confidence in their ability to care of a preterm newborn.

The mothers' prior perceptions of the newborn's abilities or how they react to environmental stimuli do not differ from what they observed after NBO. However, it is verified that the NBO confirms this perception and broadens the mothers' understanding of the meaning of the newborn's behavior. A similar study was found in a study performed with mothers in the postpartum period, indicating that NBO increases the mothers' knowledge of newborn capacities ${ }^{10}$.

This finding is in line with discussions about maternal sensitivity, which can be understood as the ability of the mother to accurately perceive and interpret the signals and communications of the newborn and respond appropriately to them. Maternal sensitivity 
is a broad concept that includes a variety of correlated affective and behavioral attributes such as affection, flexibility, acceptance, negotiation of conflicts, and maternal awareness of newborn signs. It is not static and takes place in a dynamic process that involves the maternal abilities to recognize, interpret, and respond to newborn signs. In situations where the newborn's response to the mother's care or behavior does not match what is expected, the mother reinterprets the newborn's signs and responds again in other ways. Thus, in addition to the mother's ability to interpret, maternal sensitivity includes the ability of the newborn to transmit signals indicating whether their needs are being met $^{22}$. From this perspective, it can be affirmed that NBO promotes maternal sensitivity, which is expressed by the amplification of the mother's capacity to interpret the newborn's behaviors and to identify ways of attending it.

Mothers have recognized the importance of observing the newborn to learn about them and their preferences. Because it is an individualized observation system, the NBO gives the newborn the "voice with a signature," enabling him to communicate to the caregiver "who he is, what his preferences are, what his vulnerabilities are, and what areas he may need of support" $", 22$.

Participating in the NBO helped mothers identify strategies to meet the newborn's care needs, qualifying the care they have already done and opening up new possibilities for maternal care. It is recognized that parents can be helped to provide a favorable environment for the development of the newborn by understanding the need for sleep, adequate positioning, feeding and reducing stressful situations for the newborn ${ }^{23}$. It is necessary to help them identify newborn responses to different stimuli such as touch, maternal voice, ambient light and noise, as well as to modify care practices in order to maintain the comfort and physiological stability of the newborn ${ }^{23}$.

In this perspective of maternal involvement in care, the NBO is an instrument that aims to support health professionals in the identification and description of competencies and individuality of the newborn ${ }^{11}$. Considering the data obtained in this study, it can be concluded that the use of NBO by the professionals who attend the preterm newborn and his/ her family, can contribute to the qualification of the assistance insofar as it subsidizes both the planning of the care oriented by the necessities of the newborn as to the provision of guidelines to parents from what was observed by them.

The NBO in this study had an average duration of 33 minutes. Because it is a quick and easy instrument to implement ${ }^{11}$, it can be considered feasible to incorporate it into the work process of health professionals who assist the preterm newborn in the different contexts, be it in the hospital, outpatient clinic or domicile. It should be noted that the use of NBO requires specific training, which can be configured as a limitation for its large scale use.

The NBO adopts a philosophy of care that is characterized by being focused on the newborn and family centered, which favors interaction between parents and newborns ${ }^{11}$. These characteristics are in agreement with the theoretical frameworks that underlie public health policies, such as the Kangaroo Method, which focuses on low birth weight infants ${ }^{14}$. It is an attention that is not limited to the technological advances of the last years, but is based mainly on the rapprochement of parents and newborns ${ }^{24}$.

This study presents strengths and limitations. First, the fathers or other caregivers of the newborn were not interviewed, which may have different responses than those obtained with the mothers. Another relevant aspect is the fact that newborns were already in a period of greater clinical stability and were expected to be discharged from hospital, and the use of NBO in a context of greater complexity was not explored. Additionally, it is recognized that the use of the qualitative methodology offers some limitations regarding the transferability and the results for other contexts.

It is recognized that the in-depth analysis of the mothers' experience in the implementation of the NBO provided information that may stimulate the incorporation of this instrument into clinical practice and indicates the need for it to be explored in other care contexts as well. Further quantitative and qualitative studies may be useful in assessing NBO use with different family members, varied cultures, and care settings.

with potential to be used by them to care for the child in the hospital context and after discharge.

\section{Thanks}

To the team of the Care and Grow Together Project that contributed to the data collection. possible for mothers to recognize, understand and respond to the behavioral signs of the newborn through practices

\section{REFERENCES}

1. Whittingham K, Boyd RN, Sanders MR, Colditz P. Parenting and prematurity: understanding parent experience and preferences for support. J Child Fam Stud. 2015; 24(5):1529. DOI: http://dx.doi.org/10.1007/s10826-015-0166-y

2. Fleck P. Connecting mothers and infants in the neonatal intensive care unit. Newborn Infant Nurs Rev. 2016;16(2):92-6. DOI: http://dx.doi.org/10.1053/j.nainr.2016.03.007 
3. Raines DA. Mothers' stressor as the day of discharge from the NICU approaches. Adv Neonatal Care. 2013;13(3):181-7. DOI: http://dx.doi.org/10.1097/ANC.0b013e318285fa2a.

4. Maguire CM, Bruil J, Wit JM, Walther FJ. Reading preterm infants' behavioral cues: An intervention study with parents of premature infants born <32 weeks. Early Hum Dev. 2007; 83(7):419-24.

DOI: http://dx.doi.org/10.1016/j.earlhumdev.2007.03.004

5. Newnham CA, Milgrom J, Skouteris $\mathrm{H}$. Effectiveness of a modified mothering infant transaction program on outcomes for preterm infants from 3 to 24 months of age. Infant Behav Dev. 2009; 32(1):17-26.

DOI: http://dx.doi.org/10.1016/j.infbeh.2008.09.004

6. Schroeder M, Pridham K. Development of relationship competencies through guided participation for mothers of preterm infants. J Obstet Gynecol Neonatal Nurs. 2006;35(3):358-68. DOI: http://dx.doi.org/10.1111/j.1552-6909.2006.00049.x

7. Melnyk BM, Crean HF, Feinstein NF, Fairbanks E. Maternal anxiety and depression after a premature infant's discharge from the neonatal intensive care unit: explanatory effects of the creating opportunities for parent empowerment program. Nurs Res. 2008; 57(6):383-94. DOI: http://dx.doi.org/10.1097/NNR.0b013e3181906f59

8. Ra JS, Lim J. Development and evaluation of a video discharge education program focusing on mother-infant interaction for mothers of premature infants. J Korean Acad Nurs. 2012; 42(7):936-46. DOI: http://dx.doi.org/10.4040/jkan.2012.42.7.936

9. Cheetham NB, Hanssen TA. The Neonatal Behavioral Observation System: A tool to enhance the transition to motherhood. Vard Nord Utveckl Forsk. 2014; 34(4):48-52. http://dx.doi.org/10.1177/010740831403400410

10. Sanders LW, Buckner EB. The newborn behavioral observations system as a nursing intervention to enhance engagement in first-time mothers: feasibility and desirability. Pediatr Nurs. 2006; 32(5):455-9.

11. Brazelton TB, Nugent JK. The neonatal behavioral assessment scale. $4^{\mathrm{a}}$ ed. London: Mac Keith Press; 2011.

12. Nugent JK, Keefer CH, Minear S, Johnson LC, Blanchard Y. Understanding newborn behavior and early relationships: the newborn behavioral observations (NBO) system handbook. Baltimore: Paul H. Brookes Publishing Co; 2007.

13. Nugent JK. The competent newborn and the neonatal behavioral assessment scale: T. Berry Brazelton's legacy. J Child Adolesc Psychiatr Nurs. 2013; 26(3):173-9. DOI: http://dx.doi.org/10.1111/jcap.12043

14. Brasil. Ministério da Saúde. Atenção humanizada ao recém-nascido de baixo peso: Método Canguru. 2. ed. Brasília: Ministério da Saúde; 2011.

15. Dittz ES, Sena RR, Motta JAC, Duarte ED. Cuidado materno ao recém-nascido na unidade de terapia intensiva neonatal: possibilidades e desafios. Cienc Enferm. 2011; 17(1): 45-55. DOI: http://dx.doi.org/10.4067/S0717-95532011000100006

16. Guimarães MAP. O comportamento de recém-nascidos de risco: adaptação transcultural e utilização clínica da Neonatal Behavioral Observation (NBO). Dissertação (Mestrado) - Escola de Educação Física, Fisioterapia e Terapia Ocupacional da Universidade Federal de Minas Gerais. Belo Horizonte: 2016.

17. Minayo MCS. O desafio do conhecimento: pesquisa qualitativa em saúde. 13. ed. São Paulo: Hucitec; 2013.

18. Hsieh HF, Shannon SE. Three approaches to qualitative content analysis. Qual Health Res. 2005; 15(9):1277-88. DOI: http://dx.doi.org/10.1177/1049732305276687

19. Lincoln YS, Guba EG. Naturalistic inquiry. London: Sage Publications; 1985.

20. Evans T, Whittingham K, Sanders M, Colditz P, Boyd RN. Are parenting interventions effective in improving the relationship between mothers and their preterm infants? Infant Behav Dev. 2014;37(2):131-54. DOI: http://dx.doi.org/10.1016/j.infbeh.2013.12.009

21. Craig JW, Glick C, Phillips R, Hall SL, Smith J, Browne J. Recommendations for involving the family in developmental care of the NICU baby. J Perinatol. 2015;35( Suppl 1):S5-8. DOI: http://dx.doi.org/10.1038/jp.2015.142

22. Nugent JK. The newborn behavioral observation (NBO) system as a form of intervention and support for new parents. Zero Three. 2015; 36(1):2-10.

23. Altimier L. Mother and child integrative developmental care model: a simple approach to a complex population. Newborn Infant Nurs Rev. 2011;11(3):105-8. DOI: http://dx.doi.org/10.1053/j.nainr.2011.06.004

24. Freitas JO, Camargo CL. Discutindo o cuidado ao recém-nascido e sua família no método mãe-canguru. Rev Bras Crescimento Desenvolv Hum. 2006; 16(2):88-95. DOI: http://dx.doi.org/10.7322/jhgd.19794 


\section{Resumo}

Introdução: $\mathrm{Na}$ assistência ao recém-nascido pré-termo são recomendadas práticas que favorecem a participação das mães no cuidado. O uso de instrumentos apropriados pelos profissionais pode contribuir para o fortalecimento da participação materna.

Objetivo: Analisar as contribuições do uso da Newborn Behavioral Observations (NBO) para o cuidado materno de recém-nascidos prematuros.

Método: Estudo qualitativo descritivo, utilizando observação participante e entrevista semi-estruturada, com 14 mães de recém-nascidos pré-termo que realizaram a NBO. Os dados foram submetidos à análise temática de conteúdo, assistida pelo software MAXQda 12.

Resultados: Verificou-se que a percepção prévia das mães em relação às capacidades do recémnascido ou ao modo como ele reage aos estímulos do ambiente não difere do que foi observado e relatado por elas após a NBO. Entretanto, verifica-se que a realização da NBO confirma essa percepção e amplia a compreensão das mães acerca do significado do comportamento do recém-nascido. Participar da NBO favoreceu que as mães identificassem estratégias para atender às necessidades de cuidado do recém-nascido, qualificando o cuidado já realizado por elas e abrindo novas possibilidades para o cuidado materno.

Conclusão: A NBO é um instrumento que favorece o aprendizado da mãe sobre o comportamento do recém-nascido e contribui para a construção de práticas com potencial para serem utilizadas por elas no cotidiano do cuidado. Isso nos permite considerá-la um instrumento que favorece a relação mãefilho, contribui para a participação da mãe no cuidado, e apóia a mãe na construção da sua autonomia para a continuidade do cuidado do recém-nascido após a alta hospitalar.

Palavras-chave: prematuro, interação mãe-filho, mães, comportamento materno, cuidado do lactente

${ }^{\odot}$ The authors (2017), this article is distributed under the terms of the Creative Commons Attribution 4.0 International License (http://creativecommons.org/licenses/by/4.0/), which permits unrestricted use, distribution, and reproduction in any medium, provided you give appropriate credit to the original author(s) and the source, provide a link to the Creative Commons license, and indicate if changes were made. The Creative Commons Public Domain Dedication waiver (http://creativecommons.org/publicdomain/ zero/1.0/) applies to the data made available in this article, unless otherwise stated. 